\title{
O Processo de trabalho dos Agentes Comunitários de Saúde
}

\author{
The Work process of Community Health Workers \\ El Proceso de trabajo de los Agentes de Salud Comunitarios
}

Recebido: 22/12/2020 | Revisado: 24/12/2020 | Aceito: 26/12/2020 | Publicado: 01/01/2021

Gisetti Corina Gomes Brandão

ORCID: https://orcid.org/0000-0001-8040-5435

Universidade Federal de Campina Grande, Brasil

E-mail: gisettibrandao@gmail.com

Débora de Souza Lucena

ORCID: https://orcid.org/0000-0003-2992-3856

Universidade Federal de Campina Grande, Brasil E-mail: deborasoouza22@gmail.com

Jardel Marcelle dos Santos Monteiro

ORCID: https://orcid.org/0000-0002-1962-9189

Universidade Federal de Campina Grande, Brasil E-mail: jardel.marcelle@hotmail.com

João Henrique Barbosa Neto

ORCID: https://orcid.org/0000-0002-8794-2775

Universidade Federal de Campina Grande, Brasil E-mail: jhenriquebneto@gmail.com

José Roniere Morais Batista

ORCID: https://orcid.org/0000-0002-9055-7544

Universidade Federal de Campina Grande, Brasil E-mail: roniere@gmail.com

Kamylla Soares Nunes

ORCID: https://orcid.org/0000-0001-6429-6558 Universidade Federal de Campina Grande, Brasil E-mail: kamyllasoares27@gmail.com

Leilane Mendes Vilar

ORCID: https://orcid.org/0000-0002-7027-6868

Universidade Federal de Campina Grande, Brasil

E-mail: leilanevilar9@gmail.com

Stephany da Silva Santos

ORCID: https://orcid.org/0000-0002-6506-9311

Universidade Federal de Campina Grande, Brasil

E-mail: ste-silva15@outlook.com

\section{Resumo}

Objetivo: Caracterizar o perfil dos Agentes Comunitários de Saúde, e identificar os processos que facilitam e os que dificultam o trabalho dos ACSs. Método: A análise do material empírico oriundo das entrevistas semiestruturadas, com os ACSs do município de Campina Grande- PB, Brasil, escolhidos de forma não probabilística e por conveniência, realizadas no período de maio de 2018 à agosto de 2019, se deu através da análise de conteúdo de Bardin, e sua categorização a partir do Iramuteq 0.6. O estudo teve caráter descritivo-exploratório, de abordagem qualitativa, sistemática e subjetiva. A presente pesquisa foi aprovada pelo Comitê de Ética em Pesquisa (CEP) do Hospital Universitário Alcides Carneiro, CAAE $\mathrm{n}^{\circ}$ 65858717.9.00005182. Resultados: Nas falas dos ACSs, identifica-se que os mesmos reconhecem sua importância como agentes facilitadores do serviço, vinculando UBS e comunidade, além do seu papel educativo e seu conhecimento experiente e íntimo aos usuários. Por outro lado, reforçam as dificuldades como a falta de EPIs, dificuldades para lidar com violência doméstica, e na comunidade, há falta de vacinas e outros insumos, e carência no apoio da gestão. Conclusão: Em síntese, a falta de articulação no serviço se mostra o maior impecílio para a efetividade da assistência à comunidade por meio dos ACSs.

Palavras-chave: Agente comunitário de saúde; Serviço de saúde; Trabalho; Estratégia saúde da família; Gestão em saúde; Administração de serviços de saúde; Saúde pública.

\section{Abstract}

Objective: To characterize the profile of Community Health Workers, and to identify the processes that facilitate and hinder the work of CHWs. Method: The analysis of the empirical material from semi-structured interviews, with CHWs from the city of Campina Grande-PB, Brazil, chosen in a non-probabilistic and convenient way, carried out from May 2018 to August 2019, was carried out through content analysis of Bardin, and its categorization from Iramuteq 0.6. The study had a descriptive-exploratory character, with a qualitative, systematic and subjective approach. This research was approved by the Research Ethics Committee (CEP) of the Hospital Universitário Alcides Carneiro, CAAE n 65858717.9.00005182. Results: In the statements of the CHWs, it is identified that they recognize 
their importance as agents that facilitate the service, linking UBS and the community, in addition to their educational role and their experienced and intimate knowledge to users. On the other hand, they reinforce difficulties such as lack of PPE, difficulties in dealing with domestic violence, and in the community, there is a lack of vaccines and other inputs, and a lack of management support. Conclusion: In summary, the lack of articulation in the service proves to be the greatest obstacle to the effectiveness of assistance to the community through CHWs.

Keywords: Community health worker; Health service; Work; Family health strategy; Health management; Health services administration; Public health.

\section{Resumen}

Objetivo: Caracterizar el perfil de los Agentes Comunitarios de Salud e identificar los procesos que facilitan y dificultan el trabajo de los TSC. Método: Se realizó un análisis del material empírico de cambios semiestructurados, con CHA del municipio de Campina Grande-PB, Brasil, elegidos de forma no probabilística y conveniente, realizado de mayo de 2018 a agosto de 2019, a través de Análisis de contenido de Bardin y su categorización de Iramuteq 0.6. El estudio tuvo un carácter descriptivo-exploratorio, con un enfoque y especificaciones cualitativos y sistemáticos. Esta investigación fue aprobada por el Comité de Ética en Investigación (CEP) del Hospital Universitário Alcides Carneiro, CAAE n 65858717.9.00005182. Resultados: En las declaraciones de las ACS se identifica que reconocen su importancia como agentes facilitadores del servicio, vinculando a UBS y la comunidad, además de su rol educativo y su conocimiento experimentado e íntimo a los usuarios. Por otro lado, refuerzan dificultades como la falta de EPP, las dificultades para enfrentar la violencia doméstica y comunitaria, la falta de vacunas y otros insumos y la falta de apoyo a la gestión. Conclusión: En línea, la falta de articulación en el servicio resulta ser el mayor obstáculo para la efectividad de la asistencia a la comunidad a través de los TSC.

Palabras clave: Agente de salud comunitaria; Servicio de salud; Trabajo; Estrategia de salud de la familia; Gestión de la salud; Administración de servicios de salud; Salud pública.

\section{Introdução}

Considerado mundialmente como um dos maiores serviços de saúde pública, o Sistema Único de Saúde (SUS) tem como princípios a integralidade, universalidade e equidade do acesso à saúde pela população (Faria; Paiva, 2020). Dentre suas principais ações está a Estratégia de Saúde da Família (ESF), que por meio da Atenção Primária à Saúde (APS) demanda a reorientação dos processos de trabalho ampliando a resolutividade e impactando na situação de saúde individual e coletiva dos usuários dos serviços (Pedebos; Rocha; Tomasi, 2019).

A equipe da ESF deve ser composta obrigatoriamente por médicos, enfermeiros, auxiliares de enfermagem e Agentes Comunitários de Saúde (ACS), os quais devem construir uma porta de entrada nas redes de atenção à saúde, por meio da coordenação do cuidado e da ordenação das ações e serviços disponibilizados (Brasil, 2017). Assim, essa equipe multiprofissional deve estar organizada de uma maneira que contemple os usuários dos serviços sob uma visão holística que prioriza as particularidades e os contextos plurais que atravessam a vida dessas pessoas, superando dessa forma o modelo biomédico predominante.

No Brasil, o ACS simboliza efetivamente a junção entre a ESF e a comunidade, desempenhando importante papel na consolidação do SUS através de relações assistenciais de vínculo e de cuidado (Lopes et al., 2018; PINTO et al., 2017). O Programa de Agentes Comunitários de Saúde (PACS), oficialmente implantado pelo Ministério da Saúde em 1991, intenta encontrar alternativas para a melhoria das condições de saúde dos usuários por meio de trabalhadores da comunidade que atuam na própria comunidade. Trata-se de um programa fundamental para o fortalecimento da APS, entretanto, a mais recente Política Nacional de Atenção Básica (PNAB) reduziu o quantitativo dos ACSs nas equipes de saúde, o que revela uma desatenção preocupante diante da importância que esse profissional imprime no dia-a-dia do serviço (Brasil, 2017).

O processo de trabalho do ACS acontece na área de abrangência em que ele reside, no espaço onde pulsa a vida, para além dos muros das UBS (Garcia et al, 2019). Esses profissionais utilizam no seu cotidiano ações educativas, de prevenção de agravos e de promoção e vigilância da saúde e, como agente social, eles organizam e transformam suas próprias condições de vida. Além disso, os ACSs atuam no cadastro e no levantamento de informações sobre os moradores do território e possíveis fatores de risco (Coelho; Vasconcellos; Dias, 2018). 
Os profissionais da enfermagem são historicamente responsáveis pela capacitação, supervisão e acompanhamento das ações dos ACSs, sanando dúvidas e direcionando as ações de cuidado (Coelho; Vasconcellos; Dias, 2018). Para tanto, é necessário que os enfermeiros reconheçam o ACS como portador de saber de suma importância no processo de saúde-doença da população, aprimorando o seu trabalho através de estratégias imprescindíveis, como a Educação Permanente em Saúde (EPS).

Assim sendo, é importante deter conhecimento da maneira como se dá o processo de trabalho do ACS dentro da ESF, compreendendo quais são os fatores que contribuem e limitam suas atividades para que haja um fortalecimento e um direcionamento significativo da Atenção Primária à Saúde na evolução das práticas dos serviços enquanto necessidade dos usuários do sistema. Logo, este estudo tem como objetivos caracterizar o perfil dos Agentes Comunitários de Saúde e constatar quais são os aspectos da realidade diária que facilitam e os que dificultam seu processo de trabalho no contexto da Atenção Primária à Saúde.

\section{Metodologia}

Trata-se de uma Pesquisa de Campo de caráter descritivo-exploratório, com abordagem qualitativa, sistemática e subjetiva (Pereira et al., 2018; Piana, 2009). A mesma foi realizada no munícipio de Campina Grande, Paraíba, Brasil, no período de maio de 2018 a Agosto de 2019. A supramencionada teve como população os ACS, que trabalham nas Unidades Básicas de Saúde do município e seus respectivos distritos. A amostragem foi não probabilística de conveniência, sendo os critérios de inclusão: A atuação como ACS; maioridade legal; disponibilidade para responder às perguntas do estudo, e assinarem o Termo de Consentimento Livre e Esclarecido.

Para coleta de dados, utilizou-se o método de entrevista semiestruturada, permitindo a liberdade de discorrer diante de um foco principal anteriormente estabelecido pelo pesquisador (Lima, 1999). A entrevista era composta pelos dados sociodemográficos dos ACS e perguntas relacionadas ao Processo de Trabalho em Saúde, permitindo a explanação dos saberes e vivências dos mesmos, e foram realizadas a partir da adequação ao horário de trabalho dos ACS, sendo realizadas nos respectivos locais de trabalho.

A análise de conteúdo escolhida foi a proposta por Bardin, composta por quatro etapas operacionais, sendo estas: organização da análise, codificação, categorização e inferência (Bardin, 2011, p. 9). Realizou-se a coleta a partir da gravação de voz para futura transcrição do dito, compondo assim o corpus documental da pesquisa. Após transcrição fidedigna, os dados foram gerenciados a partir de um único operador, Iramuteq 0.6.

A árvore de codificação utilizou-se de análise léxica, e após redução dos vocábulos às suas raízes obteve-se, na primeira pergunta, um total de ocorrências de 6370 palavras diferentes com 647 formas distintas. O Número de Textos (UCI) foi de 57, repartidos em 187 Unidades de Segmentos de Textos (UCE). Já na segunda pergunta, ainda utilizando-se da análise léxica e reduzindo os vocábulos às suas raízes, obteve-se 8118 ocorrências de palavras diferentes, com 776 formas distintas. Além de 57 UCI, repartidos em 198 UCE.

Além disso, os temas foram organizados previamente e estruturados nas perguntas abertas do roteiro semiestruturado. Sendo assim, apenas as categorias de resposta foram derivadas para cada um dos dois temas. A pesquisa foi aprovada pelo Comitê de Ética em Pesquisa (CEP) do Hospital Universitário Alcides Carneiro, sob CAAE nº 65858717.9.00005182, e respeitou a Resolução do Conselho Nacional de Saúde nº 466/12. 


\section{Resultado e Discussões}

\section{Caracterização do perfil sócio-demográfico}

Os sujeitos deste estudo foram em sua maioria mulheres, estes possuíam em média 40,6 anos de idade e contavam com formação de ensino superior, distribuídas nas seguintes áreas: saúde coletiva, saúde da família, saúde do trabalhador, saúde pública, enfermagem do trabalho, gestão hospitalar, urgência e emergência e enfermagem em Unidade de Terapia Intensiva (UTI).

Para alcançar os objetivos desse estudo, foram construídas duas categorias temáticas segundo as etapas da análise de conteúdo de Bardin: Desvelando o processo de trabalho em saúde no planejamento das linhas de cuidado e O ACS como integrador entre a equipe e a comunidade potencializando a informação em saúde. Estas categorias foram construídas a partir das falas dos ACS, baseadas nas perguntas: 'Como ocorre seu Processo de Trabalho?', e 'Quais as fragilidades/dificuldades que você encontra no seu dia a dia de trabalho?'.

Figura 1: Como ocorre seu processo de trabalho?

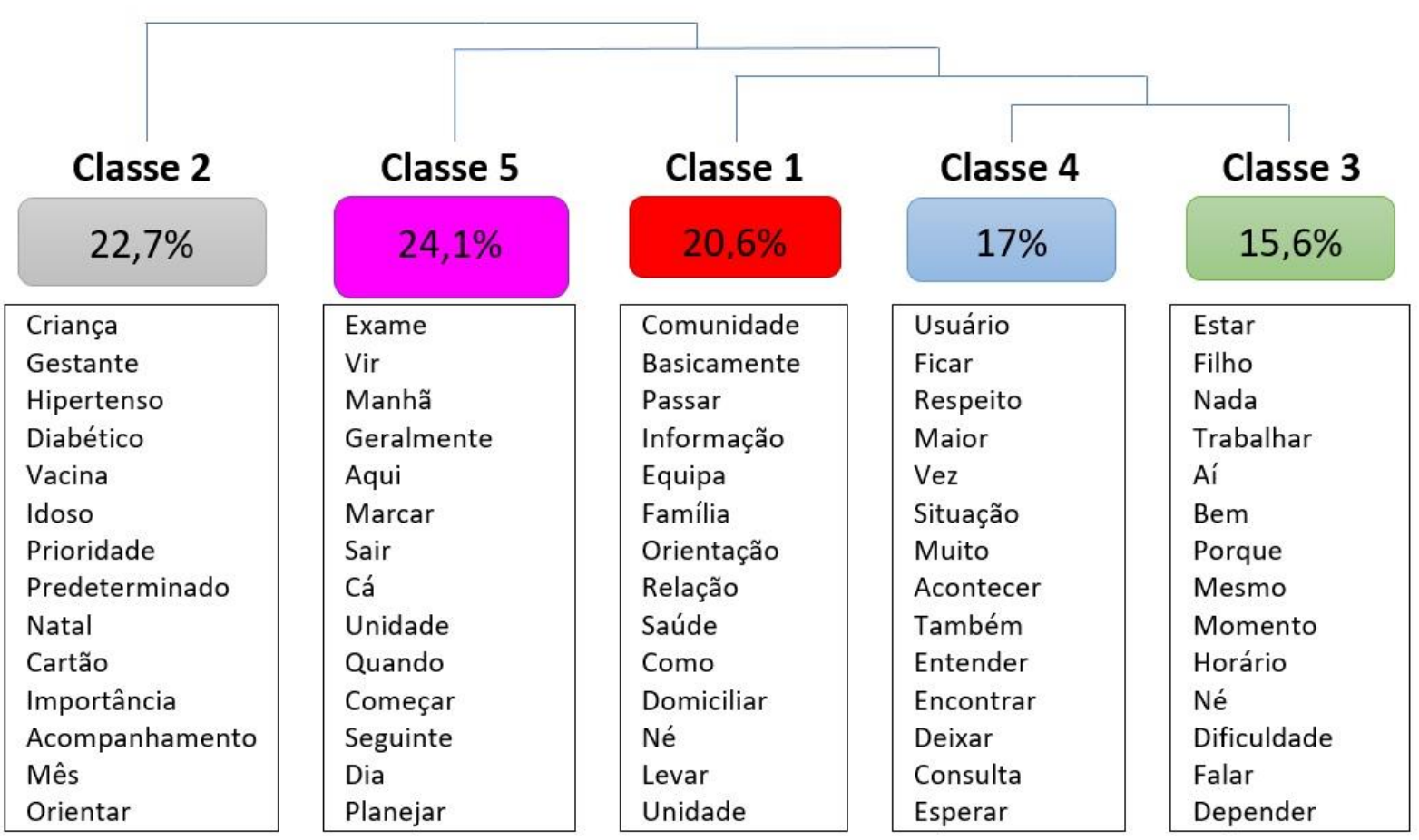

Fonte: Iramutek (2019). 
Figura 2: Quais as fragilidades/dificuldades que você encontra no seu dia a dia de trabalho?

\begin{tabular}{|c|c|c|c|c|}
\hline Classe 5 & Classe 4 & Classe 3 & Classe 2 & Classe 1 \\
\hline $15.2 \%$ & $26,8 \%$ & $26,3 \%$ & $19.2 \%$ & $12.5 \%$ \\
\hline $\begin{array}{l}\text { Agente } \\
\text { Saúde } \\
\text { Receber } \\
\text { Ainda } \\
\text { Comunitário } \\
\text { Entregar } \\
\text { Visita } \\
\text { Relação } \\
\text { ACS } \\
\text { Também } \\
\text { Ano } \\
\text { Fardamento } \\
\text { Existir } \\
\text { Mês }\end{array}$ & $\begin{array}{l}\text { Exame } \\
\text { Consulta } \\
\text { Marcar } \\
\text { Passar } \\
\text { Dificuldade } \\
\text { Marcação } \\
\text { Gestão } \\
\text { Insumo } \\
\text { Unidade } \\
\text { Atendimento } \\
\text { Falta } \\
\text { Atender } \\
\text { Gestante } \\
\text { Dentro }\end{array}$ & $\begin{array}{l}\text { Caso } \\
\text { Sair } \\
\text { Mais } \\
\text { Né } \\
\text { Dever } \\
\text { Médico } \\
\text { Querer } \\
\text { Ficar } \\
\text { Assim } \\
\text { Sentir } \\
\text { Oferecer } \\
\text { Lado } \\
\text { Abordar } \\
\text { Certo }\end{array}$ & $\begin{array}{l}\text { Área } \\
\text { Encontro } \\
\text { Droga } \\
\text { Plano } \\
\text { Porta } \\
\text { Visitar } \\
\text { Sequela } \\
\text { Risco } \\
\text { Criança } \\
\text { Como } \\
\text { Saber } \\
\text { Comunidade } \\
\text { Carente } \\
\text { Chegar }\end{array}$ & $\begin{array}{l}\text { Encontrar } \\
\text { Dia } \\
\text { Barreira } \\
\text { Faltar } \\
\text { Trabalhar } \\
\text { Mesmo } \\
\text { Casa } \\
\text { Adolescente } \\
\text { Entrar } \\
\text { Difícil } \\
\text { Fechado } \\
\text { Horário } \\
\text { Hoje } \\
\text { Coisa }\end{array}$ \\
\hline
\end{tabular}

Fonte: Iramutek (2019).

Das duas perguntas que originaram as figuras acima, foram geradas e categorizadas cinco classes, a partir da aproximação entre os tipos de vocabulário e o assunto dos quais se tratam. Na primeira pergunta 'Como ocorre seu processo de trabalho?' a classe 5, contém as palavras mais citadas nas respostas dos ACS durante as entrevista, com 24,1\%, e a menos predominante foi a classe 3, com 15,6\%. Na segunda pergunta 'Quais as fragilidades/dificuldades que você encontra no seu dia a dia de trabalho?' as palavras da classe 4 foram as que mais predominaram nas respostas dos ACS, com 26,8\%, e a classe 1 , contém as palavras que foram citadas com menor frequência, com 12,5\%.

\section{Desvelando o processo de trabalho em saúde no planejamento das linhas de cuidado}

Sabe-se que os Agentes Comunitários de Saúde (ACS) são fundamentais no planejamento das linhas de cuidado nas áreas e microáreas que estão sob sua responsabilidade, como pode-se observar nos discursos a seguir:

"Então é uma ligação onde um tem que saber da existência do outro a gente é vem pela manhã aí a gente se organiza se tiver algum exame pra levar a gente leva” (ACS X)

"Minha rotina é assim a gente vai para unidade aí ver o que é que tem de demanda se tiver exame se tiver alguma coisa visita para médica com a enfermeira aí a gente vai” (ACS X)

"Todos os dias a gente vem na unidade tem muitos exames que os usuários solicitam que os médicos solicitam e a gente vai entregar esses exames pela distância dos usuários” (ACS X)

O nosso estudo corrobora com Fonseca (2013) pois aponta o valor e conhecimento das áreas de onde surgem os indicadores para os usuários e compreende a atuação como conector de recursos entre o serviço e o usuário. 
Além disso, atrelado aos ACS, tem-se a noção e compreensão das necessidades reais da comunidade, pressupondo que os mesmos, em quantidade significativa, residem no território da Unidade Básica de Saúde e consequentemente fazem parte da comunidade na qual atuam. O que é de extrema significância, visto a necessidade de identificação das necessidades de saúde da própria população para um processo de trabalho mais eficaz. Conforme a fala:

“O horário se for visitar muito cedo as pessoas estão dormindo e não abrem a porta mas ai eu já sei quem acorda tarde ai já marco para ir mais tarde (ACS X)

“Eles são carentes demais moram numa área de risco na minha área mesmo é de muita droga e alcoolismo[...] “(ACS X)

Os ACS ainda encontram como um complicador para o seu processo de trabalho uma mobilidade urbana precária, que de acordo com Barcelos, (2018) deve ser vista como um direito social, visto que tem a finalidade de promover aos indivíduos o exercício dos seus direitos fundamentais. É possível observar nos trechos a seguir a a dimensão da problemática:

"Atualmente a minha maior dificuldade é a locomoção é o local onde eu trabalho porque eu estou em uma área extremamente carente são pessoas que vivem em situação dificil” (ACS X)

"São ruas sem nenhum beneficio não tem pavimentação não tem rede de esgoto a maior dificuldade é isso é o deslocamento até a área de atuação “(ACS X)

O uso de equipamentos de proteção individual (EPI's) pelos trabalhadores objetiva a proteção coletiva, sendo recomendado primordialmente, quando suas profissões oferecem riscos à exposição de agentes patogênicos e materiais biológicos (Nascimento et.al, 2017). Assim como os demais profissionais da saúde, os ACS são expostos a agentes patogênicos e/ou materiais biológicos. No entanto a falta de EPI's é uma realidade presente no cotidiano desses trabalhadores, deixando-os suscetíveis a desenvolverem determinadas patologias. Alguns dos profissionais entrevistados teceram as seguintes falas:

"Tinha agente de saúde reclamando por conta de falta de epi e ele disse que não que era entregue fardamento aos agentes de saúde duas vezes por ano e a gente sabe que é mentira e como se epi fosse só isso a gente recebeu um protetor solar em 2015 “(ACS X)

"Veio receber outro em 2017 e não é suficiente meu bolsa mesmo tá de desmanchando e ele disse que era entregue duas vezes por ano e não é então pelo amor de Deus “(ACS X)

“A questão do fardamento né a demora que a gente recebe por exemplo nessa gestão nessa atual gestão que já venha se arrastando por 6 anos a gente recebeu fardamento uma vez uma vez e a gente tem que se desdobrar” (ACS X)

Além da mobilidade urbana e a falta de EPI's, a violência também se apresenta como um problema:

"Porque eu fui fazer uma abordagem a três adolescentes sobre a droga e um mais adulto chegou a mim e disse cuidado tia que as vezes não sabe nem porque amanhece com a boca cheia de formiga” (ACS X) 
"Digo que é uma criança porque pelo tamanho dele ele pode ter acho que assim 12 a 13 anos com uma arma na segura um menino desse sabe o que aquilo pra pipocar um não demora “(ACS X)

A pesquisa de Almeida (2019) também destaca as dificuldades que os ACS tem em acessar os territórios que permeiam o percurso de trabalho diariamente, justamente pela imposição negativa e violenta de grupos, facções e pessoas envolvidas em atividades ilícitas, resultado também apontado no nosso estudo.

Destarte, o processo de trabalho dos ACS perpassa por uma variabilidade de fatores que influenciam diretamente na comunidade na qual está inserido e consequentemente no seu processo de trabalho, o que correlata o conceito de saúde destacado pela OMS, que é um bem estar biopsicossocial (Brasil, 2016). Caracterizando assim, a importância do ACS ao estabelecer um elo entre equipe, população e gestão proporcionando um cuidado integral ao usuário do SUS.

\section{O ACS como integrador entre a equipe e a comunidade potencializando a informação em saúde}

O ACS é o elo fundamental entre a equipe de saúde e a comunidade, pois o mesmo está em contato com as famílias do território e assim constroem um vínculo, possibilitando a captação de informações da situação de saúde e socioeconômica daquela população e a transmissão de informação da equipe de saúde para o usuário. Tendo, segundo Secco (2020) um papel importante entre a mediação dos saberes científicos e populares, facilitando o planejamento do cuidado para a área na qual a UBS está atuando. Como é possível visualizar nas seguintes falas:

\footnotetext{
"E um vínculo entre a comunidade e a unidade então a gente tem que orientar aquela família nova que chegou como é a unidade e avisar à unidade à equipe que tem pessoas novatas na área” (ACS X)

"Como é o processo do trabalho no dia a dia o nosso trabalho nós somos captadores de informação a gente vai até a comunidade pegar os dados que requer assim todos os tipos de dados de cada família “(ACS X)

"Meu processo de trabalho ocorre eu vou pra área né passar minhas visitas passar as informações sobre saúde educação pra o povo” (ACS X)
}

O ACS tem um papel de fundamental importância na transmissão de saberes para a população, adequando o seu vocabulário em diversos momentos para que a informação seja compreendida de forma eficaz pela comunidade. Para (Araújo, p3. 2018) "O ACS tem uma identidade diferente dos outros profissionais de saúde por ele ser um educador popular.” Essa transmissão de conhecimento ocorre por sua vez durante as visitas domiciliares periódicas aos usuários, como é perceptível no discurso abaixo:

"Meu processo de trabalho ocorre eu vou pra área né passar minhas visitas passar as informações sobre saúde educação pra o povo (ACS X)

Nessa interação entre o ACS e a comunidade, há uma troca de saberes e informações que pode colocar o ACS como informante privilegiado, a depender de como a mediação acontece (Ramos et al., 2020). Em muitos momentos, a captação desta informação é facilitada porque a maioria desses profissionais residem em sua área de atuação, possibilitando a abertura da comunidade com os mesmos. Além disso, pode-se observar que determinadas variáveis como o ACS ser do sexo masculino podem influenciar no diálogo com a comunidade, como é possível identificar na seguinte fala: 
"No meu dia a dia por eu ser homem por que muitas mulheres tem aquele como eu posso dizer uma barreira não se abre não conversa com a gente "(ACS X)

Ademais, também foram relatadas dificuldades na abordagem com mulheres que sofreram ou sofrem violência doméstica e sobre o uso de drogas, pois os mesmos não sabem como conseguir abertura para tratar dos termos acima elencados.

"É abordar uma mulher que sofre maus tratos que ela não denuncia ela oculta até com a gente que é bem amigo pra conversar, mas é uma barreira mesmo quando a gente da brecha pra entrar no assunto (ACS X)

"Uma das coisas que a gente tá encontrando muito em quase toda casa hoje em dia é um adolescente ou uma jovem que tá entrando no mundo das drogas e a gente num tem mais abertura para conversar tá difícil isso "(ACS X)

Outra queixa presente nas falas dos sujeitos foi a dificuldades em conseguir incentivo público para o abastecimento de insumos. De acordo com Broch (2017) as precárias condições de trabalho causam impactos tanto aos trabalhadores como aos serviços prestados, interferindo na integralidade da assistência e trazendo prejuízos no desempenho do atendimento.

"Trabalhar em psf ultimamente está deixando muito a desejar totalmente diferente de quando eu entrei que não faltava vacina a gente andava com os cartão bem organizado era tudo em dia e a gente fazia questão de pegar no pé das mães mesmo "(ACS X)

"Então as dificuldades que a gente encontra assim é quando faltam as coisas mesmo que deveriam ser enviadas pela secretaria entende” (ACS X)

"Olha a dificuldade maior hoje é o apoio por parte da secretaria por parte do ministério da saúde por parte de uma infinidade de coisas" (ACS X)

Também foi relatado por diversos ACS entrevistados as dificuldades no acesso ao domicílio de alguns usuários, porque alguns trabalham no horário das visitas, outros dormem, algumas casas estão fechadas e alguns destes profissionais não são aceitos nas casas.

"Muitas pessoas trabalham então pra gente ter acesso pra encontrar essas pessoas em casa é totalmente difícil e sem falar naquelas pessoas que a gente tem dificuldade de entrar na casa entende” (ACS X)

“Primeiro é encontrar as pessoas em casa, a maioria que está em casa está dormindo no horário” (ACS X)

“Tem casas fechadas, gente que trabalha o dia todo e dificulta muito o nosso trabalho aí pra encontrar essa pessoa tem que ser a noite ou em outro horário que ela possa estar” (ACS X)

Tais ausências influenciam negativamente na continuidade do processo de trabalho porque além do ACS utilizar seu tempo de trabalho na busca ativa desses usuários ausentes, muitos acabam não sendo acompanhados. 


\section{Manejo do processo de trabalho e sua relação com a gestão}

Nessa categoria as palavras mais repetidas foram: Usuário, exame, dificuldade, respeito, estar, filho, trabalhar, marcar, gestão, retorno, material, dever. As falas evidenciam uma estreita relação das dificuldades encontradas no processo de trabalho, o apoio e responsabilidade da gestão e da equipe frente a esses gargalos, como evidenciado nas falas a seguir:

“Mas a gente as vezes, infelizmente, tem que tentar sair num jogo de cintura pra sair daquela situação, pra não ficar 'de mal' na comunidade porque não é culpa da gente, é culpa da gestão do sistema, 'né' isso “(ACS X)

"[...] outra dificuldade é o retorno da gestão que não tem muitas vezes o material, falta o profissional para atender" (ACS X)

O apoio da gestão é extremamente importante na manutenção da UBS, para que os profissionais de saúde possam exercer seu papel com eficiência utilizando os recursos necessários. Em algumas falas, é possível identificar que a falta de insumos nas unidades de saúde, principalmente medicamentos, causam insatisfação nos usuários, e isso recai sobre o ACS e a equipe de saúde, que se sentem imponentes para suprir algumas das necessidades de suas áreas.

"[...] acho que as dificuldades são mais encontradas através da gestão, a falta de medicamentos, entendeu?” (ACS $\mathrm{X})$

“As dificuldades daqui 'é isso', a burocracia da gestão, porque a medicação muitas vezes não tem. O problema maior e constrangedor para nós da unidade é isso” (ACS X)

“As dificuldades são aquilo que não está no nosso alcance, aqui na unidade não 'tá' no alcance de nenhum profissional” (ACS X)

Além da questão dos medicamentos, outros recursos também não são disponibilizados para as UBS, impedindo a continuidade do processo de trabalho dos ACS e também dos outros profissionais de saúde. Faltam insumos básicos, sem os quais não há possibilidade de desempenhar o trabalho integrador que o ACS desempenha, bem como não há possibilidade de obter a resolutividade necessária pelo serviço.

"A técnica de enfermagem, por algumas vezes aconteceu esse tipo de situação, foi para dar satisfação ao usuário porque não tem uma lâmina de bisturi 'pra' fazer essa retirada, não tem uma gaze” (ACS X)

“As dificuldades que 'a gente encontramos', ela é certificada, ou seja, as pautas que nós temos é referente ao o atendimento público 'por causa que requer' de algumas coisas básicas para o trabalho e nós não temos o tablet, [que é] bem importante para ajuda a desenvolver o nosso trabalho legal “(ACS X)

Com relação às atribuições da gestão que também interferem no processo de trabalho dos ACS, pode-se citar a ineficiência na marcação de exames e de consultas com especialistas. Os entrevistados evidenciam que a demanda existe, mas seu cumprimento não é satisfatório, mesmo com a implantação recente de Sistemas que busquem otimizar essas solicitações, a exemplo do Sistema de Regulação (SISREG) do Ministério da Saúde.

“Às vezes você 'tá' esperando seis meses do ano e acontece de esperar até dois anos, o papel desaparecer, ficar preto, amarelo e às vezes a pessoa até morrer e o exame não foi marcado "(ACS X) 
“Consultas, quer seja pra uma urgência, quer seja outro médico específico... A gente para ali, entendeu? (ACS X)

"É aquela coisa... Quando não tem médico, é aquela barreira grande. Exames, principalmente ultrassom e hemograma não 'está' marcando de jeito nenhum, tem gestantes 'ganhando' seus bebês sem fazer uma ultrassom sequer, a não ser que elas consigam particular, porque não está marcando” (ACS X)

“Porque ai já é com a central, já é com o 'povo' da prefeitura, e eles vêm abordar a gente e 'diz' que somos nós quem não queremos marcar, e o que eu sinto dificuldade é nisso "(ACS X)

“A gente não tem como facilitar ou garantir para o usuário que aquele exame vai estar marcado. Depois que a gente implementou o SISREG não melhorou muito não... Patologia mesmo, a gente teve um mutirão pra marcar e depois disso não marcou mais nenhuma patologia “(ACS X)

Tanto a questão dos recursos, como a questão das marcações de exames e de consultas se associam diretamente com a falta de resolutividade que os agentes comunitários experimentam nos seus campos de prática. A população não consegue observar a efetivação das ações e, por conseguinte, não procura permanecer ou buscar os serviços de saúde da UBS. Isso é claro nos discursos dos entrevistados e representa uma problemática séria.

"Quando ele precisa de uma medicação ou tem outra queixa que nós trazemos pra cá e não se resolve, então, é uma dificuldade" (ACS X)

“As fragilidades 'é' a falta de resolução do serviço. Às vezes não depende de nós e sim de outro profissional e as dificuldades 'se encaixa' para o usuário também” (ACS X)

No que se refere ao processo de trabalho, os ACS se mostram resistentes às dificuldades e demonstram preocupação com a cobertura das residências, e com a forma que o vínculo do usuário com os integrantes da equipe pode influenciar no vínculo com este.

“Eu ando com a bolsa cheia de preservativo, às vezes chega na casa pra falar com a mãe aí 'elas diz' 'não, mas minha filha é virgem' ai a gente diz que tem que conversar sobre isso mesmo assim pois se acontecer algum dia 'né' “(ACS X)

"[...] o que contribui para o meu trabalho acontecer compreensão da comunidade a um bom trabalho em equipe né todo mundo se ajudando" (ACS X)

'O ACS precisa muito que esse elo não seja quebrado porque se uma pessoa não é bem atendida na unidade, prejudica o trabalho do ACS” (ACS X)

"Para a gente chegar na casa dar um bom atendimento, [...] quando ele vier na unidade também ser bem atendido; quando chegar na unidade tem que ter o que ele veio buscar: uma boa recepção e atendimento” (ACS X).

\section{Considerações Finais}

Evidencia-se que os ACS são peça-chave no cuidado à comunidade, capacitados para atender as demandas do seu processo de trabalho, devido a destreza em conhecer as particularidades do território e suas necessidades. Porém, nota-se que 
as maiores dificuldades são voltadas a falta de insumos, carência em capacitações e défict no apoio da gestão. Em síntese, a insuficiência de articulação no serviço se mostra o maior impecílio para a efetividade da assistência a comunidade por meio dos ACSs.

Por fim, espera-se que mais pesquisas sejam realizadas com o objetivo de identificar as dificuldades dos Agentes Comunitários de Sáude em outros distritos e Estados, com o objetivo de implementar capacitações de acordo com a individualidade destes locais e equipes de saúde. Dessa forma, é possível oferecer mais ferramentas que possibilitem que estes profissionais possam exercer suas funções com mais qualidade, potencializando consequentemente a assistência de sáude a comunidade.

\section{Declaração de conflito de interesse}

Os autores declaram não haver conflito de interesses.

\section{Financiamento}

Não houve financiamento.

\section{Referências}

Araujo, E. F. D. S., Paz, E. P. A., Ghelman, L. G., Mauro, M. Y. C., Donato, M., \& Farias, S. N. P. D. (2018). Os Agentes Comunitários de Saúde nas práticas educativas: potencialidades e fragilidades. Rev. enferm. UERJ, e18425-e18425.

Brasil (2001) Ministério da Saúde. Programa Agente Comunitário de Saúde - PACS. Brasília: Ministério da Saúde.

Brasil (2016) OPAS/OMS apoia governos no objetivo de fortalecer e promover a saúde mental da população. Recuperado de: https://www.paho.org/bra/index.php?option=com _content\&view=article\&id=5263:opas-oms-apoia-governos-no-objetivo-de-fortalecer-e-promover-a-saudemental-da-populacao\&Itemid=839\#: :text=A\%20constitui\%C3\%A $7 \% \mathrm{C} 3 \% \mathrm{~A} 30 \% 20 \mathrm{da} \% 20 \mathrm{Organiza} \% \mathrm{C} 3 \% \mathrm{~A} 7 \% \mathrm{C} 3 \% \mathrm{~A} 3 \mathrm{o} \% 20 \mathrm{Mundial}$, aus $\% \mathrm{C} 3 \% \mathrm{AAncia}$ $\% 20$ de $\% 20$ doen $\%$ C3\%A7a\%20ou\%20enfermidade\%E2\%80\%9D.

Broch, D. (2018). Desafios na atuação dos agentes comunitários: compreensão da determinação social da saúde e das condições de trabalho. 2017. 90f. Dissertação (Mestrado) - Universidade Federal do Rio Grande do Sul, Escola de Enfermagem, Programa de Pós-Graduação em Enfermagem, Porto Alegre.

da Silva, N. R., \& Barcelos, L. R. (2018). Mobilidade Urbana no Brasil: Um Direito Social. Virtuajus, 3(5), $133-152$.

do Nascimento, V. F., Terças, A. C. P., Hattori, T. Y., da Graça, B. C., Cabral, J. F., Gleriano, J. S., \& de Souza Ribeiro, G. R. M. (2017). Dificuldades apontadas pelo agente comunitário de saúde na realização do seu trabalho. Saúde (Santa Maria), 43(1), 60-69.

Fonseca, A. F., \& Mendonça, M. H. M. D. (2014). A interação entre avaliação e a atuação dos Agentes Comunitários de Saúde: subsídios para pensar sobre o trabalho educativo. Saúde em Debate, 38, 343-357.

Lima, M. A. D. D. S., Almeida, M. C. P. D., \& Lima, C. C. (1999). A utilização da observação participante e da entrevista semi-estruturada na pesquisa de enfermagem. Revista gaúcha de enfermagem. Porto Alegre. 20, 130-142.

Peres, C. R. F. B., Caldas Júnior, A. L., Silva, R. F. D., \& Marin, M. J. S. (2011). O agente comunitário de saúde frente ao processo de trabalho em equipe: facilidades e dificuldades. Revista da Escola de Enfermagem da USP, 45(4), 905-911.

Pereira, A. S., et al. (2018). Metodologia da pesquisa científica. [e-book]. Santa Maria. Ed. UAB/NTE/UFSM. Recuperado de: https://repositorio.ufsm.br/bitstream/handle/1/1582 4/Lic_Computacao_Metodologia-Pesquisa-Cientifica.pdf?sequence=1 .

Piana, M. C. (2009). A pesquisa de campo. São Paulo: Editora Unesp.

Ramos, D. L., et al. As redes de conhecimento do Agente Comunitário de Saúde. Rev. Pesqui, Rio de Janeiro, 12, $46-56$.

Scherer, M. D. D. A., Pires, D. E. P. D., \& Soratto, J. (2014). O trabalho na Estratégia Saúde da Família. In Saúde da família nos municípios brasileiros: Os reflexos dos 20 anos no espelho do futuro (pp. 521-571).

Secco, A. C., Rodrigues, P. M., Ledur, C. S., Zanatta, E., Mozzaquatro, C. O., \& Arpini, D. M. (2020). Educação Permanente em Saúde para Agentes Comunitários: um Projeto de Promoção de Saúde. Gerais: Revista Interinstitucional de Psicologia, 13(1), 1-17.

Vieira, M. (2011). Para além da comunidade: trabalho e qualificação dos agentes comunitários de saúde. EPSJV. 